\title{
Albers e Kaprow: notas sobre o saber da arte na educação Albers
}

and Kaprow: notes on the art knowledge in Education

Kelly Sabino

Universidade de São Paulo

\section{Resumo}

O presente artigo visa refletir sobre o ensino da arte a partir de uma dupla investigação: verificar o "saber da arte" presente na arte-educação e averiguar formas de entender a aula de arte como criação a partir dos procedimentos artísticos apresentados pelo "saber da arte." Traz à baila escritos dos artistas Allan Kaprow e Joseph Albers sobre as suas práticas artístico-docentes como possíveis lastros investigativos para uma prática docente baseada na criação artística. Para tanto, usa-se da perspectiva criacionista deleuziana, entendendo a arte como uma operação do pensamento. Pensar, portanto, uma aula de arte que tem como matéria-prima o pensamento e conjugá-la às pistas educativas que os próprios artistas produzem em seus trabalhos pode fomentar reflexões para além de um ensino de arte baseado em metodologias fixas e conteudistas.

Palavras-chave: arte; educação; arte contemporânea

\section{Abstract}

The present article aims to reflect on art education from a two-dimension investigation: verifying the "art knowledge" present in art-education and ascertaining ways of understanding the art class as creation through artistic procedures in the "art knowledge". It brings up writings by the artists Allan Kaprow and Joseph Albers on their artistic and teaching practices as possible investigative ballasts for a teaching practice based on artistic creation. To do so, it uses a Deleuzian perspective on creativity, in which art is a way of thought operation. Therefore, understanding an art class that has thought as primary material and relating it to educative clues that the artists produce in their works may boost reflections beyond an art education based on fixed methodologies and content programs.

Revista Digital do LAV - Santa Maria - vol. 9, n. 1, p. 162 - 176. - jan./abr. $2016 \quad$ ISSN 1983 - 7348 http://dx.doi.org/10.5902/1983734822061 
Kelly Sabino

Keywords art; education; contemporary art

Educação artística, arte e educação, educação através da arte, Arte/Educação, nomenclaturas que, apesar dos diferentes enfoques e abordagens, revelam, sobretudo, o desejo de inscrever a arte na educação. Para Carmen Biasoli (1999, p.86), no final do século $X X$, era possível afirmar que, visto a miscelânea de vertentes entre os termos, "a educação artística nas escolas não vai nada bem", para ela o que se vê é uma "pulverização de tópicos de técnicas(...) que empobrecem o verdadeiro sentido do ensino da arte".

A busca por esse sentido do ensino da arte parece ser premissa das pesquisas na área. Ana Mae Barbosa (1990, p. 7) afirma que "para que as décadas futuras sejam mais promissoras para a arte-educação, é necessário, primeiro romper com o preconceito de que a arte-educação significa apenas arte para crianças e adolescentes e afirmar arte-educação como investigação dos modos como se aprende arte na escola."

Eis a questão: como se aprende arte na escola? Talvez o diagnóstico apresentado se deva ao que afirmam as pesquisadoras Ferraz e Fusari (1992, p. 20): "muitos professores propõem atividades às vezes totalmente desvinculadas de um verdadeiro saber artístico." Nos caberia uma digressão, na contramão da proposição de Barbosa e da afirmação de Ferraz e Fusari, ao invés de pensar como se aprende arte, seria preciso pensar se há de fato "um verdadeiro saber da arte".

Muito se fala em nome de um saber da arte, mas de acordo com Cayo Honorato (2011, p. 26), o ensino da arte, "por vezes, pressupõe ou promove uma relação mais ou menos imediata entre arte e educação, seja ao modo de uma junção ou de um pertencimento recíproco, talvez por recear a desterritorialização em que seria lançado, caso assumisse essa inconformidade."

A noção de "saber da arte" aparece no notável texto do crítico Ronaldo Brito chamado O moderno e o contemporâneo, de 1980. Para Brito, a passagem da modernidade para a contemporaneidade é a pedra de toque para o entendimento das práticas não só atuais, como também de um regime de significação interno da arte. Não mais entendida como Belas-Artes - dividida em linguagens e gêneros -, mas como apresenta Thierry de Duve, a "arte em geral", pela sua possibilidade de

Revista Digital do LAV - Santa Maria - vol. 9, n. 1, p. 162 - 176. - jan./abr. 2016 ISSN 1983 - 7348 http://dx.doi.org/10.5902/1983734822061 
tornar qualquer coisa arte, traz à tona uma discussão que extrapola aquilo que, comumente, é apresentado na escola.

Poder fazer arte com tudo que há disponível nos posiciona diante de uma rede discursiva que, por um lado, apresenta um saber que institui e legitima o que é arte, e por outro, um sistema de práticas artísticas que operam o colapso do primeiro. É nas vanguardas modernas, em suas rupturas em relação aos suportes tradicionais, que vemos a insurgência de duas forças que corroboram para a constituição da arte contemporânea: uma primeira, que configura uma espécie de academicismo de vanguarda - manutenção de uma tradição dentro das vanguardas. E uma segunda, que representa uma quebra de pacto entre o que se instituía como arte.

Ronaldo Brito nos fala que, ao se afastar do estatuto que Ihe fora durante séculos conferido - cópia do real, comprovando uma unidade do olhar vinculada aos tradicionais meios com os quais ela operava -, vemos na modernidade, uma primeira disparidade entre a arte e sua institucionalização.

Ainda seguindo com o crítico de arte, como uma espécie de golpe, a arte moderna fere a si própria para salvar-se, numa tentativa de separar-se do estatuto que a vinculava ao belo, à unidade e à tradição, e ao mesmo tempo reivindicar para si o que Ihe era próprio, fazendo tensionar aquilo que parecia unitário, uma espécie de "insuspeitada distinção" entre o valor e o produto da arte. Pode-se dizer que se trata de uma disjunção, mas que obviamente uma faz parte da outra, sem serem coincidentes. Seria (BRITO, 2001, p. 204) "dessa diferença, [que] passa às vezes sob silêncio, [que] a arte moderna tirou sua força de emergência (...), pois "as linguagens da arte, subitamente evidenciou-se, não criavam o próprio valor. Este era construído, fabricado, pela estrutura burocrático-ideológica que as cercavam." ${ }^{1}$ De acordo com Duve, essa tradição foi incorporada pela modernidade sob a forma por ele chamada de academicismo de vanguarda e herdamos disso a sensação de que tudo e qualquer coisa pode ser arte. Fazendo uma analogia com uma anedota, Duve nos diz que assim como o rei, o artista passa a transformar tudo o que toca em ouro. Certamente, este legado advém do trabalho de embate trazido não apenas por Duchamp e a invenção do ready-made, mas também - seguindo com um exemplo de Ronaldo Brito - por Picasso, para além da leitura cooptada pelo sistema

Revista Digital do LAV - Santa Maria - vol. 9, n. 1, p. 162 - 176. - jan./abr. 2016 ISSN 1983 - 7348 http://dx.doi.org/10.5902/1983734822061 
da arte, que transforma em conteúdo, toma seus traços mais superficiais e formais institucionalizando-o.

Seria possível afirmar que desde a modernidade vemos na existência de um funcionamento e de uma racionalidade próprios dos discursos da arte que configuram o "saber da arte". Mas contraditoriamente, este saber produz, insistindo em operar por brechas e fendas na rede discursiva criada em torno da arte, um apanhado de discursos em torno da pluralidade, caracterizando a produção artística na contemporaneidade.

A discussão é complexa, pois esses procedimentos, essas "manobras de estranhamento", como as descreve Ronaldo Brito, parecem não estar em jogo na construções discursivas da arte-educação acima citadas, que aparentam pouco se debruçar sobre as especificidades do contemporâneo, categorizando, inclusive, a própria arte como um elemento universal. Neste sentido, é possível que a arteeducação esteja se furtando às especificidades do "saber da arte", (BRITO, 2005 , p. 5) "resumida assim a uma cronologia empírica, esquece, prefere esquecer, a luta que se trava no campo simbólico para tratá-lo como espaço neutro, contínuo e indiferenciado."

Nesse ponto, vale retomar a afirmação de Ferraz e Fusari, pois apesar de apresentarem algum reconhecimento da questão, não é feito qualquer aprofundamento que opere com o saber da arte, ao contrário, no seu desenvolvimento a desconsideração daquele saber vai sendo reiterada como, por exemplo (FERRAZ; FUSARI, 1992, p. 20): "o que se nota, então, é um afastamento dos princípios mínimos que norteiam um ideário artístico, cultural e social," sem contudo definir quais seriam tais ideais, assim como quando afirmam que o ensino de arte deve atender a uma "mobilidade conceitual" da arte. Porém que mobilidade seria esta?

A julgar pela produção artística de sala de aula vista em simples busca na internet nota-se que a arte-educação pouco se endereça ao saber produzido pelo trabalho de arte, e assim, prefere trabalhar com aquilo que Brito chamou de "estrutura de códigos vigentes de inteligibilidade". Ou seja, prefere operar a partir de estruturas que não levam em consideração a criação como um processo imprevisível, como já apresentou Duchamp e tantos outros artistas. Assim, é possível perceber, com Pierangelo Maset (2014, p.31) que a

Revista Digital do LAV - Santa Maria - vol. 9, n. 1, p. 162 - 176. - jan./abr. $2016 \quad$ ISSN 1983 - 7348 http://dx.doi.org/10.5902/1983734822061 
[...] a educação artística está situada em um campo de contradição entre a liberdade da obra estética e o trabalho baseado em tarefas das instituições em geral e as expectativas que cercam as escolas em particular. Não é de admirar que, nos últimos anos, a educação artística como operação técnica tenha se tornado norma. Isso tem levado a um estreitamento do conteúdo artístico, mesmo quando "bem-sucedido" e "viável".

Contudo, referências ao saber da arte como as apresentadas por Ferraz e Fusari aparecem com alguma insistência em textos da área, e que no geral, quando reconhecem tal afastamento, buscam uma (re)unificação entre arte e arteeducação. Como nos apresenta Honorato, "chama a atenção que alguns desses textos tragam como título expressões ou questões que sugerem uma separação entre arte e educação (momentos em que esses campos se entreolham de lugares diferentes), mas também uma vontade de ligação. São eles: "Devolvendo arte à arte-educação" (1984) de Vincent Lanier, "A arteeducação precisa dos artistas" (1984) de Ana Mae Barbosa, e "O que pode a educação aprender das artes sobre a prática da educação?" (2002) de Elliot Eisner." A amostra selecionada por Honorato (2011) é pequena porém precisa, a partir da análise dos textos feita pelo autor é possível perceber que todos parecem convergir no que diz respeito ao endereçamento que fazem ao saber da arte, assumindo-se como um saber sobre a arte desvinculado do próprio "saber da arte".

Em tempo, valeria nos questionarmos sobre qual discurso a arte-educação se endereça à arte como um saber epistemológico? Ora, são notórios os esforços empreendidos por pesquisadores na década de 1980 para inscrever a arte na educação sob o signo do conteúdo (BARBOSA, 1989, p. 171): "um simpósio foi planejado [agosto, 1989] para demonstrar os conteúdos da arte na educação. Apesar de termos a maioria dos arte-educadores das escolas secundárias defendendo o laissez-faire e alguns outros que ainda não aceitam autoexpressão, o caminho para sobreviver é tornar claro os possíveis conteúdos da arte na escola".

Sob a perspectiva apresentada, que conteúdo ensina a arte?

A arte-educação se estrutura como uma metodologia que entende a arte como conteúdo, esse conteúdo - oposto à "palavra" - é entendido como imagem e disso voltamos à releitura e à leitura de imagem. Nota-se, portanto, que o esforço

Revista Digital do LAV - Santa Maria - vol. 9, n. 1, p. 162 - 176. - jan./abr. $2016 \quad$ ISSN 1983 - 7348 http://dx.doi.org/10.5902/1983734822061 
consiste em uma espécie de instrumentalização do olhar, ignorando (BARBOSA apud HONORATO, 2011, p. 95) "a capacidade da arte em transcender modelos de apreensão [teorias e técnicas]. (...) O que se ensina são, em geral, modelos de apreensão, ou seja, precisamente aquilo que reduz a arte à condição de objeto, de conhecimento, como qualquer outro [conteúdos de representação históricos, sociais, psicológicos etc.]".

Decerto, tal empreitada é herdeira de uma estruturação típica do paradigma moderno chamada pelo pensador francês Thierry de Duve de tríade "criatividademeio-invenção". Entretanto, seria correto imaginar maneiras nas quais a tal tríade pudesse ser replicada ao contexto contemporâneo, cujas tensões extrapolaram as questões dos meios. Uma possível resposta para a hegemonia de um tipo de arte que circula nas salas de aula, a ver pelas referências à Tarsila do Amaral, Portinari, Picasso e Da Vinci bastante reconhecidas pelos meus alunos, talvez, se dê pela dificuldade de operar com a tríade apresentada por De Duve, no complexo contexto contemporâneo.

Em linhas gerais, a conjunção entre um conhecimento específico da arte e sua distribuição na sala de aula a partir da revisão dos elementos que compõe suas linguagens supõe que conhecer arte (FERRAZ; FUSARI, 1992, p.81) "implica num envolvimento cognitivo, perceptível e sensível com as formas dessas imagens." O que significaria que o ensino da arte, além de produzir imagens e contextualizá-las, deve também analisá-las em função dos meios pelos quais são feitas. Destrinchando a arte em uma linguagem decodificável, à maneira de Kandinsky, dá-se um papel para o aluno e do ponto se faz a linha e depois o plano, etc. Ou, então, a instrumentalização buscada pela leitura de imagens terá como apoio formal, não as categorias trazidas pelos meios, seja pintura, seja escultura ou seja o que for, mas uma suposta "linguagem visual", uma espécie de estruturação lexical do desenho que, ao acrescentar o estudo das cores, ampliase para o entendimento da pintura.

Se reduzida a isso a aula de arte corre um risco bastante danoso, pois se "elabora uma análise plástica das obras - desconstrução dos componentes composicionais ou cromáticos, etc. - e considera a obra como um edifício formal que será o resultado de um saber-fazer, e raramente de um saber-pensar, e que aparece como uma espécie de molde operatório". Priorizando o saber-fazer do artista, reafirmase o caráter virtuoso e genial da arte; priorizando o ensino dos meios e reforçando a linguagem artística (DUVE, 2012, p.65) "passamos inevitavelmente a fetichizar 
os meios em sua autonomia". E, ainda, mais gravemente, com isso ensina-se que a arte só se faz pelos meios, como se fosse impossível a existência de uma arte fora deles - fato que desconsidera em absoluto o saber da arte e a produção artística contemporânea.

Entretanto, não se pretende com isso afirmar que a arte possa prescindir de seus meios e especificidades; de forma alguma, porém, um ensino de arte cujo foco esteja centrado nos códigos das modalidades artísticas pode tornar-se uma experiência vazia.

Contudo, não se pretende ignorar a importância histórica do produção teórica em torno da visualidade já produzida, a tomar como principal exemplo a Bauhaus de Itten e Klee. Haja visto que, justamente por seu modelo baseado nas corporações de ofícios - em que cada sala tinha um artista "mestre da forma" e um artesão "mestre dos materiais" -, a própria concepção e ensino bauhausiana contribuiu para a desmitificação da teoria do gênio na arte.

Ainda que no interior da escola alemã, como é de conhecimento geral, houvesse duas vertentes antagônicas em disputa: uma, centrada na objetividade e na função social de Max Bill e Walter Gropius, e outra, voltada para a interiorização e espiritualização em torno da arte, de Klee e Kandinsky, a ideia que norteava a função do artista estava, em primeiro lugar, em seu caráter social e sua relação direta com a educação e, em segundo, comprometida com a criação contínua como produção do real, através de uma linguagem visual.

\section{Joseph Albers - Pensar em situações}

Albers, exímio artista e educador da Bauhaus, Black Mountain College e Yale, apresenta para nós, professores de arte, uma excelente pista operacional que vai, inclusive, na contramão de um ensino pautado da especificidade dos meios artísticos.

Em uma palestra para seus alunos na Black Mountain College, Joseph Albers propõe algo que, naquela época, era distante do que se pensava em arte e educação, pois, para Albers (GOLDBERG, 2006, p. 111) "arte diz respeito ao como e não ao o quê; não ao conteúdo literal, mas à representação do conteúdo factual." Ou seja, o artista propunha em seu curso sobre o estudo da cor, além de pensá-la como algo

Revista Digital do LAV - Santa Maria - vol. 9, n. 1, p. 162 - 176. - jan./abr. 2016 ISSN 1983 - 7348 http://dx.doi.org/10.5902/1983734822061 
absoluto - uma teoria a ser replicada -, que seu estudo fosse feito por suas interações e, sobretudo, pela experimentação.

O principal objetivo de Albers em educação era ajudar seus alunos a enxergarem com acuidade; por isso a importância em conhecer a fundo os elementos da linguagem visual. No entanto, a linguagem visual não era, segundo Albers, (HOROWITZ; DANILOWITZ. 2006, p. 90) um dado puro em si; suas aulas discorriam sobre os postes de luz de Nova Iorque, sobre a anatomia de insetos, monumentos, etc., pois o artista estava convencido de que nenhum elemento (seja ele da linguagem visual ou não) possa existir fora de um contexto.

Assim, em seu livro A interação da cor, de 1963, Albers apresenta seu conceito de educação com arte, "segundo ele pouco conhecido e cultivado na época (HONORATO, 2011, p. 147): "pensar em situações". A proposta não é casual. Depois de se dar conta de que "a cor é o meio mais relativo dentre os utilizados na arte", Albers entende não fazer mais sentido que seus cursos se iniciem com a apresentação de sistemas e teorias da cor, passando a enfatizar a experimentação."

Com a formulação de um ensino de arte baseado na experimentação - e de que esta não está nem um pouco descolada da vida, dos objetos, paisagens etc. - o lugar do professor é daquele que apresenta situações-problemas a partir de experiências; os resultados serão compartilhados e desconhecidos por ambos, professor e aluno. Ou seja, trata-se de um processo de aprendizagem mútua.

As aulas de Albers (é possível assistir parte de seu trabalho como professor em um documentário silencioso disponível no site de sua fundação) são enérgicas, os alunos andam pela sala, usam o corpo para desenhar um círculo no ar, afastam-se e aproximam-se pela linha do olhar de um objeto. Elas corroboram a afirmação que destrinchar elementos da linguagem visual em si não potencializam uma aprendizagem experimentadora em arte.

Albers se opõe ao que ele acredita ser a tônica da aula de arte, normalmente composta pela dupla teoria-prática, nesta ordem. Ao contrário disso, o "pensar em situações" pressupõe que (ALBERS, 2009, p. 92) "a prática não é precedida, mas sim seguida pela teoria", visando uma aprendizagem em arte pautada pela experiência. Curiosamente, apesar do caráter experimental e colaborativo da prática educacional de Josef Albers ter tido uma grande influência na arte-educação estadunidense, na literatura brasileira acerca da área há pouco reconhecimento do 
seu legado. Uma possível justificativa está no fato de que seu trabalho, a ver pelos seus escritos, está no embate constante com a ideia de pesquisa, de ensino e de prática docente que ele propunha - o que não aparece como a tônica dos textos de arte-educação, especialmente após sua estruturação, entre 1980-1990, cujo foco parecia estar mais centrado no discurso que configurava elementos para se definir a arte como conteúdo e não que a pusessem em xeque.

Para Albers (HOROWITZ; DANILOWITZ, 2006, p. 73), o principal trabalho do professor de arte seria "to make open the eyes" algo aparentemente simples, mas de implicações complexas: ver com acuidade significa desaprender a ver por padrões pré-estabelecidos, estar aberto para o novo. Assim, Albers concluía que o que há de possível em ensinar arte residia em apreender profundamente através de um olhar sensível e atento aos elementos da arte, sendo o restante "inensinável" e fruto do pensamento artístico de cada um.

\section{Allan Kaprow - Mover coisas, apertar botões}

Um outro artista que nos fornece importantes lastros pedagógicos em sua trajetória é Allan Kaprow. Após dois anos da morte do expoente do expressionismo abstrato Jackson Pollock (1912-1956), Kaprow (2009, p. 38) escreve uma carta na qual, junto ao seu pesar pela perda, apresenta um novo rumo para a arte pós-Pollock. Através da pergunta: "Não era perfeitamente claro que a arte moderna em geral estava definhando?". Kaprow, que havia abandonado a pintura, associa a morte de Pollock com a morte da arte moderna.

Allan Kaprow (2009, p. 38) conclui que, após a radicalidade imposta por Pollock, "temos de passar a nos preocupar com o espaço e os objetos da nossa vida cotidiana, e até mesmo a ficar fascinados por eles, sejam nossos corpos, roupas e quartos". Ou seja, tratava-se da continuação daquilo que Pollock ensinou à sua geração - uma ação que transbordou os limites pictóricos, saiu para a rua e invadiu a vida.

Allan Kaprow, além de notório artista, foi um grande teórico da arte e produziu textos cruciais para o entendimento das manifestações artísticas das décadas de 1960 e 1970. Com os happenings, Kaprow, para além da idiossincrasia que o termo

Revista Digital do LAV - Santa Maria - vol. 9, n. 1, p. 162 - 176. - jan./abr. 2016 ISSN 1983 - 7348 http://dx.doi.org/10.5902/1983734822061 
nomeou para manifestações dessa natureza na arte, propôs uma nova postura tanto do artista quanto do espectador.

Em 1959, Kaprow fez o "18 happenings in 6 parts", que consistia em 18 ações apresentadas por ele e seis amigos em três salas da Reuben Gallery de Nova Iorque. Havia consignas ao público que, no programa da apresentação, eram colocados como parte do elenco. Era possível transitar entre as três salas ao toque de uma sirene e, se o público quisesse aplaudir, só poderia fazê-lo ao final da apresentação (e não entre as ações). Foi essa experiência que cunhou o termo happening que, segundo Kaprow (2010, p. 1), significa "um jogo, uma aventura, um número de atividades acordadas entre os participantes por e pelo jogo".

Nos "18 happenings in 6 parts", Kaprow (2010, p. 2) havia decidido "aumentar a 'responsabilidade' do observador", convocando uma presença mais ativa do público. Nos convites feitos para esse trabalho, Kaprow imprimiu: "Você se tornará parte dos happenings; irá vivenciá-los simultaneamente". Dessa forma, com Kaprow, o termo "espectador" dá lugar à ideia de "participante", pois este se transforma em agente do trabalho, e passa a participar da obra.

Os happenings contestavam as convenções artísticas, mesclando artes plásticas, teatro, música e radicalizando em todas essas linguagens. Como diz Kaprow (2010, p. 2), com os happenings, foram dadas aos espectadores "oportunidades, tais como: mover coisas, apertar botões.(...) [e isso] sugeriu a necessidade de dar mais responsabilidade ao espectador (...) até chegar ao happening".

Assim, a aproximação entre arte e vida em Kaprow se dava em duplo sentido: primeiro da arte para a vida - tornar os participantes dos happenings conscientes (presentes) em seu cotidiano, por mais trivial que este fosse. E pela entrada da vida na arte - pela desinstitucionalização da arte e sua restrição ao métier especializado. Assim, dando continuidade a essa pesquisa, Kaprow passou dos happenings, já incorporados pela crítica como uma nova modalidade artística, às Activities, obras que não mais tinham o intuito de serem assistidas, pois se tratavam de roteiros que poderiam ser seguidos por qualquer pessoa em qualquer lugar.

Na década de 1970, Kaprow escreve a trilogia The Education of the Unartist, partes I, II e III (1971, 1972 e 1974, respectivamente). Nesses textos,

Revista Digital do LAV - Santa Maria - vol. 9, n. 1, p. 162 - 176. - jan./abr. $2016 \quad$ ISSN 1983 - 7348 http://dx.doi.org/10.5902/1983734822061 
Kaprow nos apresenta "senhas" sobre a arte: non-art, un-art, art-art e pos-art. Trata-se de meios de endereçamento da arte em sua relação com a vida e que culminaram no conceito de (KAPROW, 1993, p. 201) lifelike art - um modo de fazer arte como a vida, embaraçando e destituindo as fronteiras entre os termos em uma tomada de posição crítica perante a vida. As ações são realizadas dentro da vida, de acordo com um caráter ético e político (KAPROW, 2014): "O anartista não faz arte real, mas o que chamo de arte como-a-vida [lifelike art], arte que nos faz principalmente nos lembrar das nossas vidas".

Para Kaprow, a questão educativa talvez seja a principal solução para apresentar novas possibilidades de jogar-brincar na vida, e, para isso, a educação precisa de an-artistas.

Já em um outro artigo, chamado "Sucessos e fracasso quando a arte muda", Allan Kaprow (2009) descreve uma aproximação mais efetiva entre arte e educação através do relato de uma experiência em colaboração com escolas de Bekerley.

Kaprow, como parte do seu projeto lifelike art, encampou no início da década de 1960 um projeto chamado Outros Caminhos junto com o educador Hebert Kohl, cuja principal intenção era dar um lugar central às artes no currículo da escola pública. O projeto aconteceu em uma espécie de loja localizada perto de uma escola pública, mas que recebia passantes e outras escolas, desde poucos alunos até professores e turmas inteiras.

O foco do trabalho estava no básico "leitura, escrita e matemática", pois acreditavam que a arte favorecia a aprendizagem desses e de outros assuntos. $O$ projeto durou cerca de dois anos e era avesso aos discursos pedagogizantes em torno da arte. Nesse artigo, Kaprow (2009, p. 151) faz uma cuidadosa avaliação dessa empreitada, tentando deslocar a questão do sucesso ou fracasso dessa ação para uma reflexão acerca do potencial da arte produzida na década de 1960: "o 'Projeto Outros Caminhos' tinha, porém, a intenção de fundir arte com outras coisas não consideradas arte, sobretudo o aprendizado em leitura, redação, matemática, e assim por diante. Significativamente os inovadores movimentos artísticos daquele momento forneceram os modelos para nossos objetivos".

No entanto, o ponto principal que essa experiência aponta não parece recair sobre o sucesso ou não dessa experiência educativa, mas sim em seu endereçamento. Era arte? Era educação? A ambiguidade de sua identidade era ao 
Kelly Sabino

que se propunha o artista, para quem seus trabalhos deveriam sempre se manter nessa espécie de limbo indefinido (Kaprow, 2009, p. 151): "Podem a arte experimental e a educação experimental andar juntas mais substancialmente para o bem comum?".

A partir das reflexões artísticas trazidas à baila, parece possível imaginar uma aula de arte cujo pano de fundo pudesse ser calcado no procedimento artístico impregnado tanto no trabalho docente, quanto naqueles artistas elencados para serem trabalhados. Apesar de vermos no contexto artístico atual o aumento da participação do público como algo banal, o mesmo não pode ser dito daquilo que se pratica na escola. Ainda que por excelência a disciplina "Arte" advenha de operações e ações práticas de cada aluno implicado em seu trabalho, não se pode afirmar que esse seja um pressuposto de aula, pois muitas vezes, diante da falta de recursos para trabalhar, professores optam por cursos de história da arte e/ou desenho.

Com Kaprow, é possível entender a aula de arte como uma experiência, um acontecimento. E trabalhar o acontecimento requer aquilo que Kaprow nos fala: "estar atento" é equilibrar-se como um acrobata que se orienta ora pelo gesto proposto, ora pela recepção e devolutiva do aluno, pois o acrobata (CORAZZA, 2004 , p. 3) "requer operações que se movimentem: dos corpos e estados de coisas aos acontecimentos; das misturas às linhas puras; da superfície corporal à metafísica do pensamento puro". Enfim, essa presença escapa à noção de arte como conteúdo e às demais configurações da arte que circulam na educação, pois se relaciona com aquilo que, parafraseando Lyotard, é o "impresentificável".

Finalmente, a partir de Albers e Kaprow, é possível pensar a aula como uma obra de arte, não no sentido mercadológico - hoje imperativo, pois não se trata de reivindicar um lugar no sistema da arte, mas de potencializar a ação, as forças e trazer o corpo para a experiência, atentos aos gestos, transformando, segundo Sant'Anna (2001, p. 99) "o corpo em um território de ressonâncias destituído de todo o autismo."

Tanto professor quanto aluno podem, nessa relação, dentro do universo da sala de arte, operar por lógicas que ultrapassem a representação, idealização e exibição, em uma direção assertiva e de resistência, atrás da construção de um novo lugar, onde o professor siga propositor e participante.

Revista Digital do LAV - Santa Maria - vol. 9, n. 1, p. 162 - 176. - jan./abr. 2016 ISSN 1983 - 7348 http://dx.doi.org/10.5902/1983734822061 
Um ensino que privilegie as linhas e observe os planos de imanência, os volumes e suas qualidades, que enxergue, em suma, o movimento na e da matéria - ao invés de se propor a sistematizá-la em conteúdos, por vezes, desconectados da vida - tende a ser um conjunto simples, porém complexo, que tem dentro da aula de arte a matéria vida como principal conteúdo. Pois (ZORDAN, 2010, p. 11), "o que se procura ao pensar o que é a matéria das artes não é instituir programas formalizados, tampouco elencar conteúdos ou definir uma 'linguagem' e sim produzir a amostragem das variadas maneiras pelas quais é possível tratar uma matéria, inventando e aprendendo modos de ensiná-la". Por fim, de Albers a Kaprow, o conteúdo da aula de arte é muito vasto - o que quer que se apresente como potência para a aula de arte que o seja no sentido de experimentação como recusa ao excesso de tecnicismo que envolve a educação como um todo. Para tanto, é preciso que haja sensibilidade do professor para lidar com as mais diversas linhas que compõem a aula, o outro e a si próprio, fazendo com isso composições que aumentem a potência de si e do outro, que façam ranger os elementos estáticos de uma arte sem latência para uma arte como experimentação de vida.

Nesse sentido, uma aprendizagem em arte que leve em consideração uma experimentação colaborativa, na qual professor e aluno sejam postos diante de situações-problema, possibilita que os alunos, segundo Albers (2009, p. 100) "não apenas encontrem soluções próprias para problemas conhecidos, como também visualizem e descubram novos problemas, novas soluções e novas apresentações". Haja visto que junto a Deleuze (1998, p. 288) "não são os começos nem os fins que contam, mas o meio. As coisas e os pensamentos crescem ou aumentam pelo meio, é aí onde é preciso instalar-se, é sempre aí que isso se dobra".

\section{Referências}

ALBERS, Joseph. A interação da cor. São Paulo: Martins Fontes, 2009.

BARBOSA, Ana Mae. Arte-Educação no Brasil: realidade hoje e expectativas futuras. Estud. av. [online]. 1989, vol.3, n.7. pp. 170-182. Disponível em: <http://www.scielo.br/scielo.php?script=sci_arttext\&pid=S010340141989000300 $010 \&$ Ing $=e n \& n r m=i s o>$. Acesso em 29/06/2015.

Revista Digital do LAV - Santa Maria - vol. 9, n. 1, p. 162 - 176. - jan./abr. $2016 \quad$ ISSN 1983 - 7348 http://dx.doi.org/10.5902/1983734822061 
BIASOLI, Carmen Lúcia Abadie. A formação do professor de arte: Do ensaio...à encenação. Campinas: SP. Papirus, 1999.

BRITO, R. ; DE LIMA, S. ; Experiência crítica. São Paulo: Ed. Cosac Naify, 2005.

CORAZZA, Sandra M. Pesquisar o currículo como acontecimento em v exemplos. Disponível em: <http://27reuniao.anped.org.br/gt12/t1211.pdf>. Acesso em 13/07/2015.

DELEUZE, G. PARNET, C. Diálogos. trad. Eloísa Araújo Ribeiro. São Paulo: Escuta, 1998.

DUVE, Thierry de. Fazendo escola (ou refazendo-a?). Chapecó: Argos, 2012.

FAVARETTO, Celso. Arte Contemporânea e Educação. In: Revista

Iberoamericana de Educación. N.o 53 (2010). Disponível em:

$<w w w$.rieoei.org/rie53a10.pdf>. Acesso em 29/06/2015.

FERRAZ, M. H. C. de T.; FUSARI, M. F. de R. e. Arte na Educação Escolar. São Paulo: Cortez, 1992.

GOLDBERG, Roselee. A arte da performance - Do Futurismo ao Presente. São Paulo: Martins Fontes, 2006.

GROYS, Boris. Art power. Postmediabooks, 2012.

HONORATO, Cayo. A formação do artista: conjunções e disjunções entre arte e educação. 2011. São Paulo: Faculdade de Educação, USP. Tese de Doutorado.

HOROWITZ, F.; DANILOWITZ, B. Josef Albers: to open eyes. Nova Iorque: Phaidon, 2006.

KAPROW, Allan. Essays on the Blurring of Art and Life. Berkeley, CA: University of California Press, 1993, p. 201.

Sucessos e fracassos quando a arte muda. Arte \&

Ensaios, Rio de Janeiro, v. 18, julho de 2009. Disponível em:

<http://www.ppgav.eba.ufrj.br/wpcontent/uploads/2012/01/ae18_allan_kaprow.p df>. Acesso em 02/02/2016.

In: FERREIRA, G. e COTRIM, C. Escritos de artistas 60/70. Rio de Janeiro: Jorge Zahar, 2009.

Performing Life. Revista ARS, vol 8 , n. 15, São Paulo, 2010.

A educação do Un-artista. Revista Concinnitas, ano 5, n. 6, julho de 2014. Disponível em <http://issuu.com/websicons4u/docs/revista6/169>. Acesso em 03/05/2015.

Revista Digital do LAV - Santa Maria - vol. 9, n. 1, p. 162 - 176. - jan./abr. $2016 \quad$ ISSN $1983-7348$ http://dx.doi.org/10.5902/1983734822061 
MASET, Pierangelo. Between education and participation: Aesthetic operations. Artigo publicado na revista Engage no. 20. 2009. Disponível em: http://www.engage.org/downloads/215025048_EJ_20_P.Maset.pdf. Acesso em $15 / 07 / 2014$.

PELBART, Peter P. "A arte de viver nas linhas". In: DERDYK, E. Disegno. Desenho. Desígnio. São Paulo: Senac, 2007.

SANT'ANNA, Denise B. Corpos de passagem: ensaios sobre a subjetividade contemporânea. São Paulo: Estação Liberdade, 2001.

ZORDAN, Paola. Percursos das artes visuais: geologia de uma disciplina. Disponível em:

< http://33reuniao.anped.org.br/33encontro/app/webroot/files/file/Trabalhos\% 20 em\%20PDF/GT24-6006--Int.pdf>. Acesso em 03/06/2015. 